IN MEMORIAM

DOI: $10.24844 /$ EM3302.13

\title{
Ubiratan D'Ambrosio: El legado de una vida dedicada a la búsqueda de las matemáticas por la paz
}

\author{
Milton Rosa ${ }^{1}$ \\ Daniel Clark Orey ${ }^{2}$
}

El 12 de mayo del 2021, la comunidad mundial de Etnomatemáticas, Educación Matemática y afines, que Ubiratan D’Ambrosio sembró y cultivó, quedó consternada por la noticia de su fallecimiento.

Es innegable la importancia que tuvo Ubiratan D’Ambrosio para el desarrollo del Programa Etnomatemáticas en Brasil y, también, internacionalmente, ya que este investigador es el teórico y filósofo más importante en este campo de estudio e investigación. D'Ambrosio era el líder internacional y el principal divulgador mundial de las ideas relacionadas con las Etnomatemáticas y sus aplicaciones en la Educación Matemática a través de las conexiones entre las Matemáticas y la Cultura.

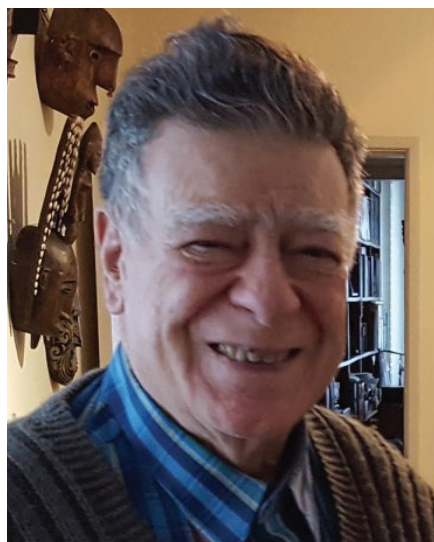

Ubiratán D'Ambrosio. Archivo personal de Milton Rosa (2019)

En sus investigaciones sobre los estudios sociales, políticos y culturales, D'Ambrosio estableció una profunda relación entre las matemáticas, la antropología y la sociedad. Por ejemplo, en 1983, D’Ambrosio fue honrado con el título de Fellow de la Asociación Americana para el Avance de la Ciencia (AAAS) por su liderazgo efectivo en la evolución de la Educación

\footnotetext{
Universidade Federal de Ouro Preto (UFOP), Milton.rosa@ufop.edu.br, Brasil.

2 Universidade Federal de Ouro Preto (UFOP), oreydc@gamil.com, Brasil
} 
Matemática en América Latina y también por sus esfuerzos dirigidos al desarrollo de la cooperación internacional.

En ese contexto, en 1997 D'Ambrosio fue considerado como el padre intelectual del Programa Etnomatemáticas y en al año 2000, este investigador fue elegido como uno de los matemáticos más importantes del siglo XX, principalmente, en relación con los temas sociales, políticos, culturales y antropológicos a través del Programa Etnomatemáticas.

En 2001, D’Ambrosio fue honrado por el Comité Internacional de Historia de las Matemáticas con el Premio Kenneth O. May por sus importantes contribuciones a la Historia de las Matemáticas y, en el 2005, fue honrado por el Comité Internacional de Instrucción de Matemáticas (ICMI) con la segunda Medalla Felix Klein por el reconocimiento a sus aportes en el campo de la Educación Matemática.

En una búsqueda de los usos pacíficos de las Matemáticas y de las Ciencias, D’Ambrosio ofreció una dirección alternativa para brindar una nueva perspectiva a su trabajo en la Educación Matemática. Ha sido particularmente interesante profundizar en esta exploración de sus reflexiones sobre la globalización, los mitos y la religión porque D'Ambrosio también estaba preocupado con el desarrollo de las ticas del matema en diferentes etnos.

D'Ambrosio siempre se preocupó por la supervivencia de la humanidad que depende de nuestra relación con la naturaleza, que está regulada por principios ecológicos. Entonces, para comprender a los seres humanos, así como a las otras especies, D'Ambrosio enseñó que dependemos esencialmente del análisis de una tríada: individuos-sociedad-naturaleza, bien como de la efectividad de las relaciones entre ellas.

En este sentido, la supervivencia y la trascendencia han sido, a lo largo de la historia, las raíces del conflicto, que se desarrolla en el enfrentamiento, la violencia y el sometimiento de los individuos y la naturaleza.

Actualmente, el gran desafío para todos nosotros es poder enfrentar los conflictos, que son intrínsecos a la vida. Es un derecho innegable de todos los seres humanos compartir los bienes culturales y naturales necesarios para nuestra supervivencia material y superación en la búsqueda por la trascendencia intelectual.

Por medio de sus estudios, D’Ambrosio concluyó que los matemáticos, científicos e ingenieros no son los únicos que construyen, desarrollan, usan, acumulan y difunden el conocimiento matemático. Esto es porque el conocimiento se genera mediante el desarrollo de diferentes procesos, que son comunes a todos 
los miembros de grupos socioculturales que permiten a sus integrantes elaborar y utilizar las habilidades matemáticas que incluyen contar, localizar, medir, dibujar, representar, jugar, comprender y explicar las necesidades e intereses de diversos grupos. e individuos.

En este sentido, esta visión más amplia de D’Ambrosio sobre la Educación Matemática explica el dinamismo cultural dentro y entre diferentes sociedades y comunidades, a través de una acción dialógica que puede transformar el conocimiento matemático en busca del bien común. Además, los principios de D’Ambrosio son consistentes con los ideales freireanos, ya que el conocimiento matemático es dinámico, siendo considerado como el resultado del desarrollo de la actividad humana.

Durante su trayectoria personal, académica y personal, D'Ambrosio compartió con nosotros su visión de cuán fundamental debe ser que la enseñanza y el aprendizaje de las Matemáticas valoren el contexto sociocultural del conocimiento matemático y que debemos fomentar y conectar este aspecto a los diversos procesos de aprendizaje.

Este enfoque tiene como objetivo proponer metas educacionales que busquen el aprecio y respeto por los conocimientos matemáticos diversos, no solo la valorización de los currículos formales y académicos para que podamos lograr la justicia social y la paz en este momento de crisis pandémica.

Esperamos que este tributo sea significativo y relevante para la comunidad de la Educación Matemática, porque D’Ambrosio contribuyó para el desarrollo de una sociedad más justa a través de los aspectos socioculturales de las Matemáticas.

Así, a través de su liderazgo internacional, este investigador luchó por el bienestar de las personas, la preservación de los recursos naturales y culturales, que pueden sintetizarse como la paz en sus diversas dimensiones, como, por ejemplo, la paz interior, la paz social, la paz ambiental y la paz militar. 